\title{
BMJ Open The Oslo Ischaemia Study: cohort profile
}

\author{
Ragnhild Sørum Falk (D) , 'Julian Eek Mariampillai (D) , ${ }^{2}$ Erik Edvard Prestgaard (D) , ${ }^{3}$ \\ Trond Heir (1) ," Johan Bodegård (1) , ${ }^{2}$ Trude Eid Robsahm (1) , \\ Irene Grundvold (D) , ${ }^{6}$ Per Torger Skretteberg, ${ }^{2}$ Kristian Engeseth (D) ,6 \\ Jorgen Vildershoj Bjornholt (D) ,4,7 Knut Stavem (1) , 8,9 Knut Liestøl (D) , ${ }^{10}$ \\ Leiv Sandvik, ${ }^{1}$ Erik Thaulow, ${ }^{4,11}$ Gunnar Erikssen (i) ," Sverre E Kjeldsen (1) ,2,4,12 \\ Knut Gjesdal (10 ,2 Jan E Erikssen ${ }^{4}$
}

To cite: Falk RS,

Mariampillai JE, Prestgaard EE, et al. The 0slo Ischaemia Study: cohort profile. BMJ Open 2021;11:e049111. doi:10.1136/ bmjopen-2021-049111

- Prepublication history and additional supplemental material for this paper are available online. To view these files, please visit the journal online (http://dx.doi.org/10.1136/ bmjopen-2021-049111)

Received 18 January 2021 Accepted 24 September 2021

Check for updates

(C) Author(s) (or their employer(s)) 2021. Re-use permitted under CC BY-NC. No commercial re-use. See rights and permissions. Published by BMJ.

For numbered affiliations see end of article.

Correspondence to Ragnhild Sørum Falk; rs@ous-hf.no

\section{ABSTRACT}

Purpose The Oslo Ischaemia Study was designed to investigate the prevalence and predictors of silent coronary disease in Norwegian middle-aged men, specifically validating exercise electrocardiography (ECG) findings compared with angiography. The study has been important in investigating long-term predictors of cardiovascular morbidity and mortality, as well as investigating a broad spectrum of epidemiological and public health perspectives.

Participants In 1972-1975, 2014 healthy men, 40-59 years old, were enrolled in the study. Comprehensive clinical examination included an ECG-monitored exercise test at baseline and follow-ups. The cohort has been re-examined four times during 20 years. Linkage to health records and national health registries has ensured complete endpoint registration of morbidity until the end of 2006, and cancer and mortality until the end of 2017.

Findings to date The early study results provided new evidence, as many participants with a positive exercise ECG, but no chest pain ('silent ischaemia'), did not have significant coronary artery stenosis after all. Still, they were over-represented with coronary disease after years of follow-up. Furthermore, participants with the highest physical fitness had lower risk of cardiovascular disease, and the magnitude of blood pressure responses to moderate exercise was shown to influence the risk of cardiovascular disease and mortality. With time, follow-up data allowed the scope of research to expand into other fields of medicine, with the aim of investigating predictors and the importance of lifestyle and risk factors.

Future plans Recently, the Oslo Ischaemia Study has been found worthy, as the first scientific study, to be preserved by The National Archives of Norway. All the study material will be digitised, free to use and accessible for all. In 2030, the 0slo Ischaemia Study will be linked to the Norwegian Cause of Death Registry to obtain complete follow-up to death. Thus, a broad spectrum of additional opportunities opens.

\section{INTRODUCTION}

"In the 1960s, I remember very well that many young men would suddenly fall over and die. Autopsy almost always showed massive coronary atherosclerosis." (Professor Jan Emil Erikssen, Oslo, Norway)
Strengths and limitations of this study

- A strength of the Oslo Ischaemia Study is the prospective inclusion of initially healthy men from the general population with comprehensive examination at baseline and follow-ups.

- The study has high response rates at several repeated long-term follow-ups.

- Complete endpoint registration including morbidity and causes of death for all participants in the cohort, adds to the value of this study.

- The study is limited by the narrow time window for recruitment (early 1970s), weakening the relevance for following generations.

- Only middle-aged Caucasian men were included, limiting the generalisability, as the results may be different in women and non-Caucasians.

The burden of cardiovascular disease (CVD) in Norway increased dramatically after World War II, especially among men, ${ }^{1}$ and the majority of deaths among middle-aged men was due to cardiovascular causes. The prevention and treatment of acute myocardial infarctions were not effective at that time. Knowledge on CVD aetiology was sparse, but it appeared that acute events were preceded by years of developing arterial disease. Thus, it was important to identify risk factors for CVD and develop methods to detect evolving disease as early as possible.

The idea that CVD could be predicted and possibly prevented, took hold, and the hunt for cardiovascular risk factors opened a massive research field. Many surveys were established, mainly in Europe and the USA, where the Framingham Heart Study is the most well known. ${ }^{2}$ Most studies concerned patients with existing comorbidities, whereas a minority included healthy participants from the general population, usually with a limited number of variables measured at baseline. 
The Oslo Ischaemia Study is an observational prospective cohort study, initiated in 1971 at Rikshospitalet, Oslo, Norway, by then research fellow Jan Emil Erikssen, MD, and professor of cardiology Ole Storstein, MD. The study was designed by guidance of the epidemiologist and physician Geoffrey Rose at London School of Hygiene and Tropical Medicine, who was chair of the planning committee of the 'International Society and Federation of Cardiology' seminars, WHO-population approach to heart-disease prevention. At the outset, the study had no funding, but was carried out through reallocation of internal staff, volunteering and later contributions from several collaborative agencies.

The primary aim of the study was to explore the prevalence of silent coronary heart disease (CHD) in a cohort of healthy, middle-aged Norwegian men from the general population, and to gain knowledge about long-term risk factors of CHD and other CVD in presumably healthy males. In addition, the investigators specifically aimed to validate exercise electrocardiography (ECG) findings in subjects suspected to have CHD, against invasive coronary angiography, the gold standard for evaluation of coronary atherosclerosis. Over the years, new objectives and hypotheses have evolved, mainly regarding predictors for CVD and mortality, as for instance, blood pressure and heart rate responses to exercise, and impact of temporal changes in risk factors. In recent years, increased collaboration with the Cancer Registry of Norway has widened the research field to also include cancer epidemiology.

\section{COHORT DESCRIPTION}

Men aged 40-59 years, working at four major governmental agencies (Tele-communication Services, Postal Services, Custom and Excise Services, Norwegian State Railways) and one private company (Siemens) in Oslo, Norway, were invited to participate in a cardiovascular health survey, which took place between 28 August 1972 and 21 March 1975. Only agencies practicing annual or biannual health examinations of all their employees were chosen for the study. These agencies had employees from all social classes and represented both office and factory workers. The chief medical officer of each agency and the survey leader (JEE) decided eligibility of each possible participant after joint scrutiny of health records. Presence of any of the following diseases caused primary exclusion: known or suspected CVD (angina pectoris, myocardial infarction, stroke and/or other heart disease), diagnosed hypertension requiring pharmacological treatment, diabetes mellitus, thyroid disorders, cancer, advanced pulmonary, renal, or liver diseases or other serious disorders. Subjects on long-term pharmacological treatment were also excluded, as well as those who for various reasons were considered unable to conduct a bicycle exercise ECG test properly (eg, for orthopaedic, neurological or muscular reasons). These criteria served to select a group of apparently healthy, employed middle-aged men.
In total, 2341 men fulfilled these criteria and were invited to participate in the study.

An a priori sample size calculation estimated the number of participants needed to identify risk factors of CHD to be minimum 2000, which was expected to be feasible within the available space, time and economic support of the project.

\section{Survey examinations}

The examinations took place between 7:30 and 11:30 $\mathrm{am}$, and the participants were requested to abstain from smoking for at least 8 hours and eating for at least 12 hours before the examination. They had to be free from intercurrent illness and any use of medication for the past 14 days; if not, examinations were postponed at least 14 days. Two to four participants were examined each day, as each individual's baseline examination took approximately 3 hours. Baseline characteristics of the study participants are presented in table 1.

The examination consisted of nine steps (figure 1). The first step was standardised measurement of height (to the nearest $0.5 \mathrm{~cm}$ ) and weight (to the nearest $0.1 \mathrm{~kg}$ ). In the second step, lung function was assessed by spirometry, measuring the forced vital capacity and forced expiratory volume in one second with a calibrated Bernstein type bell spirometer (manufactured by a scientific instrument maker, Ullevaal hospital, Oslo, Norway), and peak expiratory flow with a Wright peak flowmeter (Airmed Ltd, Harlow, England). ${ }^{34}$ Spirometry recordings were corrected to body temperature and ambient pressure saturated with water vapour, based on daily room temperature measurements and assumption of an atmospheric pressure of $760 \mathrm{~mm} \mathrm{Hg}$.

In the third step, a biplane chest X-ray was taken, and absolute and relative heart volume $\left(\mathrm{mL} / \mathrm{m}^{2}\right.$ body surface area) were calculated by a trained radiologist.

The fourth step included blood tests. Blood sampling was performed after $5 \mathrm{~min}$ rest, with the patient sitting in half-supine position. Serum was stored in tightly sealed tubes at $4^{\circ} \mathrm{C}$ until lipid analyses were performed, usually on the same or the next day. Table 1 presents details on the blood sample analyses. For further reading on assay procedures, methods, quality control and standardisation procedures, see a previous description. ${ }^{5}$

An intravenous glucose tolerance test (IVGTT) was performed in step five: $25 \mathrm{~g}$ glucose $(50 \mathrm{~mL} 50 \%$ glucose solution) was injected over 2-3 min, via an indwelling venous cannula with subjects in a semi-prone position. Blood samples for glucose determinations were collected just before the glucose injection, immediately after its completion, and then, every 10th min for 1 hour. Because of reduced work-force, this procedure was changed to blood sampling every $15 \mathrm{~min}$ for the second half of the study population.

Then, in step six, the participants underwent a clinical interview and full clinical examination. General patient characteristics were registered, and participants were asked about previous and family history of diseases, 
Table 1 Baseline characteristics of the study cohort (1972-1975 examination), $\mathrm{n}=2014$

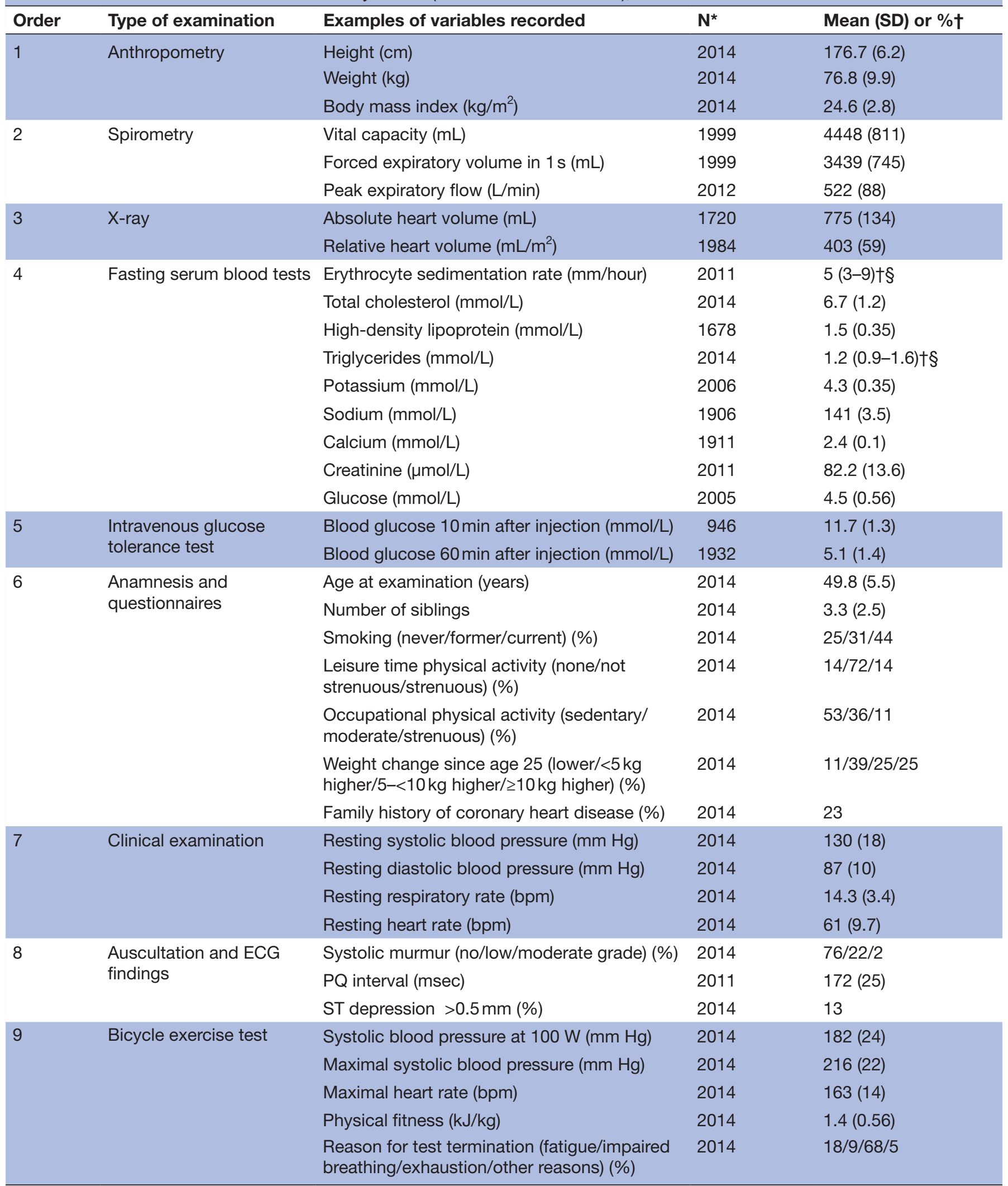

*Number of men with available information.

†Figures are given as proportion if categorical data or mean with SD if continuous data.

$\S$, Median (25th to 75 th percentile). 


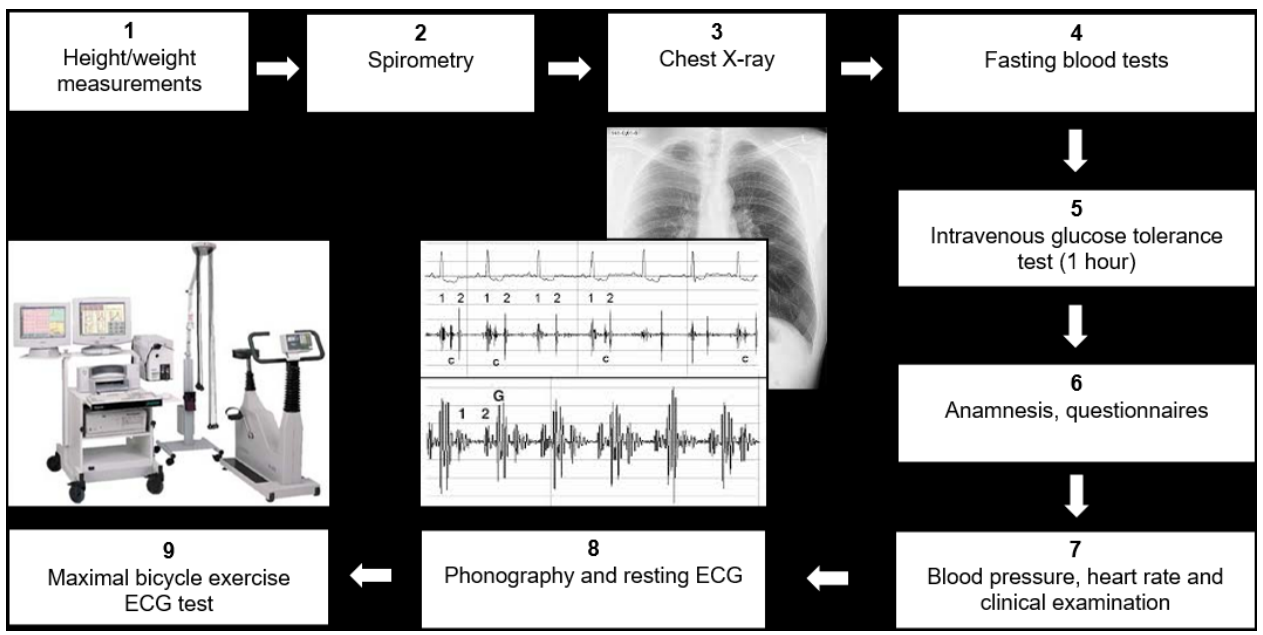

Figure 1 Baseline examination outline for one subject during the examination day. ECG, electrocardiography.

symptoms of disease (such as chest pain), smoking habits, physical activity and weight change during the preceding years. Furthermore, all participants were interviewed using a questionnaire on cough and phlegm with four questions from the British Medical Research Council (MRC) respiratory questionnaire ${ }^{6}$ and two items on breathlessness from the MRC dyspnoea questionnaire. ${ }^{7}$

On arrival for the examination, all subjects filled out the WHO Questionnaire (WHO-Q), and the answers were checked according to accepted procedures. ${ }^{7}$ All participants who answered 'yes' to the first two questions in the WHO-Q were also tested with the Greater New York Insurance Plan Survey Questionnaire (NY-Q) for angina pectoris. ${ }^{8}$ The NY-Q also applied to all individuals who had other signs or symptoms of suspect CHD.

In step seven, blood pressure to the nearest even $2 \mathrm{~mm} \mathrm{Hg}$ was measured manually with a calibrated mercury sphygmomanometer after $5 \mathrm{~min}$ rest in the supine position in a quiet room. The same physician (JEE) performed all measurements in all participants. Korotkoff sound phase 5 defined the diastolic blood pressure. Blood pressure was measured three times, and the first measurement established the approximate pressure level. The second and third measurements followed a careful procedure with first elevating the arm for venous draining, and then lowering the arm with measurements during inspiration followed by relaxed expiration. There was a small systematic fall in blood pressure from the first to the second reading, and then, on average, a minimal rise $(<1 \mathrm{~mm} \mathrm{Hg})$ from the second to the third reading. The second reading was therefore considered to be the lowest recording, and has been used as the baseline value. Resting heart rate was counted after the blood pressure measurement, by heart rate auscultation for exactly $1 \mathrm{~min}$ (using a stopwatch). Immediately thereafter, the respiratory rate was counted similarly for $1 \mathrm{~min}$.

After a complete physical examination, phonocardiography was performed to register the characteristics of heart sounds and murmurs (step eight). Then, a supine 12-lead ECG was recorded after another 5 min of rest, and resting heart rate was additionally measured from these ECGs. Various ECG variables were defined, see examples in table 1.

In the last step, an exercise test was performed under ECG monitoring using an electrically braked bicycle (ElemaSchönander AB, Solna, Sweden). The test was initiated at $600 \mathrm{kpm} / \mathrm{min}(98 \mathrm{~W})$, and the workload was increased by $300 \mathrm{kpm} / \mathrm{min}$ every $6 \mathrm{~min}$. All men were encouraged to exercise until exhaustion, or infrequently, until termination by the investigator for safety reasons. Only 15 men were unable to proceed from the initial to the second workload at the baseline examination. Submaximal termination-mainly due to chest pain, ST-depression, brief arrhythmias or patients 'unwilling to continue'-occurred in 91 men. ${ }^{9}$ Systolic blood pressure was measured after 1, 3 and 5 min on each workload and immediately prior to test termination. ECG was recorded at 2, 4 and 6 min on all loads while sitting on the bicycle, immediately prior to test termination and thereafter recumbent at $1 \mathrm{~min}$ after exercise. Heart rate recovery was measured 1 and 5 min after end of exercise. Total work capacity was the sum of work performed at all workloads, and physical fitness was defined as total work capacity divided by body weight. $^{10}$

Several sub-studies were performed during the inclusion period. (1) Thrombocyte function and coagulation properties were assessed in a random sample of the second half of the study population $(\mathrm{n}=150) ;{ }^{11}$ (2) highdensity lipoproteins and immune-reactive insulin was determined in a sub-sample of individuals $(n=269)$ in the latter part of the study period when the glucose values were measured every 15 min; ${ }^{12}$ (3) haematocrit measurements were performed in every second participant in the second half of the study period $(\mathrm{n}=488) .{ }^{13} 14$

Study participants received medical care and treatment by their general physicians when indicated. Suspicion of CHD was based on the following criteria: (1) WHOquestionnaire on angina pectoris positive on interview, (2) typical angina during a near maximal bicycle exercise test, (3) a positive exercise ECG during and/or after 


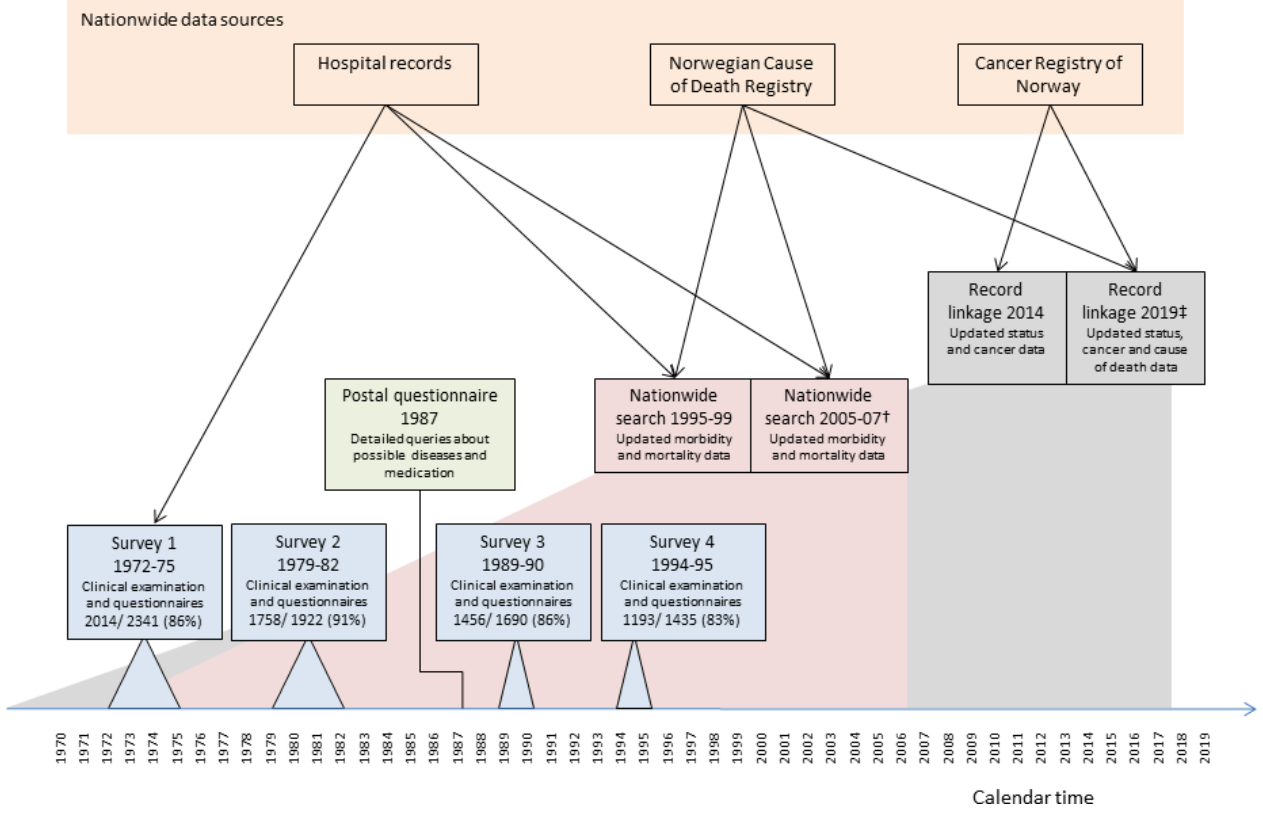

Figure 2 Flowchart of clinical examinations and follow-ups in the Oslo Ischaemia Study. Complete endpoint registration for morbidity to 1 January $2007 \dagger$, and for cancer and total mortality to 31 December $2017 \neq$.

exercise, (4) ST-segment depression on resting ECG. All individuals suspected of having CHD, underwent a repeated exercise test within 2 weeks and coronary angiography was performed within 2-3 months after the first examination in $91 \%$ of the participants with suspected CHD. ${ }^{15}$

As a primary prevention advice, all the individuals were urged to quit smoking, be physically active and to avoid weight gain. Otherwise, no active life style intervention was performed.

\section{Follow-up}

At baseline, 2014 (86\%) among the 2341 eligible men qualified for and agreed to participate (figure 2). Individuals alive in 1979-1982 were invited to a 7-year follow-up examination, survey 2, where $1758(91 \%)$ of the invited 1922 men participated. A third survey was conducted in 1989-1990, in which 1456 (86\%) of the 1690 men who were still alive, participated. A last re-examination, survey 4, was conducted in 1994-1995, where 1193 (83\%) of the 1435 invited men participated. The consecutive re-examinations were almost identical to the baseline examination, although the number of blood tests was reduced and the IVGTT was not repeated. Dedicated investigators from the study group closely supervised by the leader of the survey (JEE) performed the re-examinations.

In 1987, a postal questionnaire on morbidity and medication had a participation rate of $98.5 \%$ among the men alive. Every Norwegian resident has, since 1960, been assigned a unique personal identification number. This facilitates linkage of information from several independent sources, and is the main reason for the low loss to follow-up in this study.

Two nationwide searches of hospital records were performed in 1995-1999 and 2005-2007 (figure 2).
Updated morbidity data were obtained by manual scrutiny of hospital medical records for all participants who had been admitted to any Norwegian hospital (between the end of survey 1 and 1 January 2007). Data were obtained from all available sections in the journals (eg, history, ECG readings, outpatient notes and letters from general practitioners). In Norway, by law, all citizens have equal access to hospital care free of charge, hence reducing bias due to difference in health-seeking behaviour based on economic inequality. The Norwegian Cause of Death

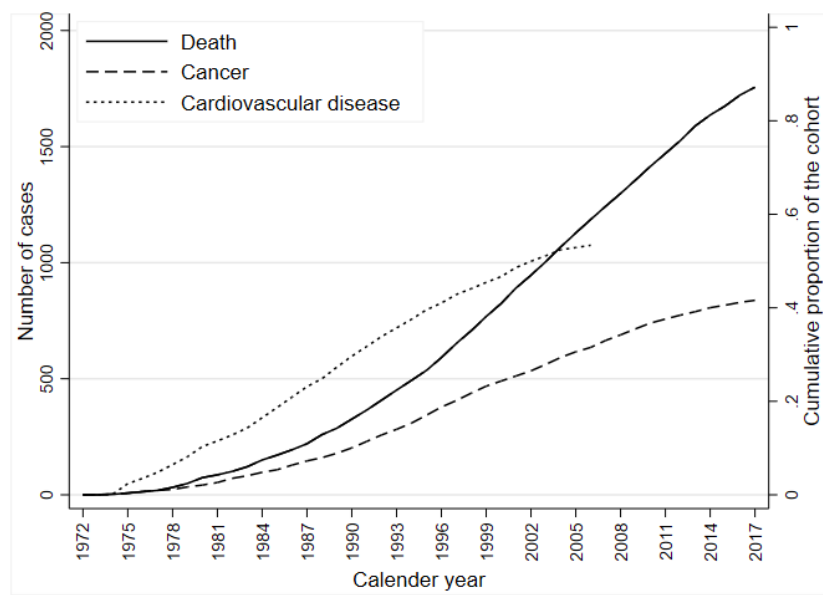

Figure 3 Cases and cumulative incidence of cardiovascular disease $\dagger$, cancer and death over 45 years follow-up in initially healthy middle-aged men. †Cardiovascular diseases included fatal or non-fatal myocardial infarction, angina pectoris, heart failure, ischaemic or haemorrhagic stroke, transitory ischaemic attack, abdominal aortic aneurysm, claudicatio intermittens and revascularised peripheral artery disease. This follow-up ended on 1 January 2007. 
Table 2 Brief overview of publications in the Oslo Ischaemia Study

\begin{tabular}{|c|c|c|}
\hline Theme & Description of main findings & Ref. no* \\
\hline Latent and future CHD & $\begin{array}{l}\text { Comprehensive results on predictors for CHD and possible impact of physical } \\
\text { fitness, as well as works on reliability of exercise ECG and CHD questionnaires }\end{array}$ & $\mathrm{S} 1-30$ \\
\hline Exercise ECG & $\begin{array}{l}\text { Small ST-depressions predict CVD, whereas rapid up-sloping ST-segment and } \\
\text { P wave terminal force do not. Repeated exercise ECG testing provides more } \\
\text { comprehensive information on CHD than single testing }\end{array}$ & $\begin{array}{l}\text { S21-25, } \\
\text { S31-36 }\end{array}$ \\
\hline $\begin{array}{l}\text { Exercise blood pressure and } \\
\text { CVD risk, and predictors of } \\
\text { exercise blood pressure }\end{array}$ & $\begin{array}{l}\text { High systolic blood pressure at a moderate workload is associated with } \\
\text { increased CVD in general, and specifically CHD, independent of resting systolic } \\
\text { blood pressure and possibly with a linear relationship }\end{array}$ & $\begin{array}{l}\text { S26-30, } \\
\text { S37-44 }\end{array}$ \\
\hline Other risk factors of CVD & $\begin{array}{l}\text { Physical fitness, blood pressure, haematocrit, erythrocyte sedimentation rate } \\
\text { and cholesterol level are independent predictors of cardiovascular death. } \\
\text { Fasting blood glucose: an underestimated risk factor for cardiovascular death }\end{array}$ & S45- 54 \\
\hline Atrial fibrillation & $\begin{array}{l}\text { Even a high normal baseline blood pressure and a marked vagal activity, } \\
\text { represented by low heart rate during moderate exercise, was associated with } \\
\text { atrial fibrillation. Physical fitness is protective against atrial fibrillation }\end{array}$ & S55-57 \\
\hline Stroke & $\begin{array}{l}\text { Systolic blood pressure at maximal work load, weight gain during early adult } \\
\text { life, but not in mid-life, is associated with increased risk of stroke. Change in } \\
\text { fitness level is associated with change in stroke risk }\end{array}$ & S58-60 \\
\hline Metabolic disease & $\begin{array}{l}\text { Fasting blood glucose, blood glucose elimination rate and triglycerides predict } \\
\text { DM2 in healthy men with normal fasting blood glucose. Maternal, but not } \\
\text { paternal history of DM2 is also an independent predictor of DM2 }\end{array}$ & S61-64 \\
\hline
\end{tabular}

Heart: rate, volume and sounds as predictors

S65-72

cardiovascular mortality. Large heart volumes in untrained men predict cardiovascular mortality. Forth heart sound has little prognostic value as a screening tool in healthy individuals

\begin{tabular}{|c|c|c|}
\hline $\begin{array}{l}\text { Pulmonary symptoms and } \\
\text { disease }\end{array}$ & $\begin{array}{l}\text { Lung function in smokers had predictive value beyond pulmonary disease, } \\
\text { as it associated with all-cause mortality. Respiratory symptoms, such as } \\
\text { breathlessness and phlegm, were independent predictors of long-term mortality }\end{array}$ & S73-77 \\
\hline $\begin{array}{l}\text { Longevity and all-cause } \\
\text { mortality }\end{array}$ & $\begin{array}{l}\text { Smoking, overweight and physical fitness are strong and independent } \\
\text { predictors of longevity }\end{array}$ & S78-83 \\
\hline Cancer & $\begin{array}{l}\text { High physical fitness is related to lower cancer risk, cancer mortality and case } \\
\text { fatality. Improved physical fitness during follow-up was associated with lower } \\
\text { cancer incidence and mortality. Serum potassium level was positively and } \\
\text { linearly related to cancer risk. Men with rapid elimination of plasma glucose had } \\
\text { higher cancer risk, and low cholesterol may be associated with increased risk of } \\
\text { prostate cancer }\end{array}$ & S83-89 \\
\hline Methodology & $\begin{array}{l}\text { There are significant seasonal variations in physical fitness during the year. } \\
\text { Exercise test termination criteria, questionnaires and order of examination may } \\
\text { impact study results. Poor correlation between measured physical fitness and } \\
\text { questionnaire-obtained occupational and leisure-time physical activity levels }\end{array}$ & $\begin{array}{l}\text { S54, } \\
\text { S89-94 }\end{array}$ \\
\hline
\end{tabular}

${ }^{*}$ Reference number refers to overview of articles in online supplemental table 1.

$\mathrm{CHD}$, coronary heart disease; CVD, cardiovascular disease; DM2, diabetes mellitus type 2; ECG, electrocardiography.

Registry contains information on all recorded deaths of Norwegian citizens living in Norway at time of death since 1 January 1951, and provided mortality data in the form of International Classification of Diseases, ninth and tenth revision (ICD-9 and ICD-10 codes), until end of 2006. All death certificates were scrutinised and quality-controlled.

In 2014, the cohort was linked to the Cancer Registry of Norway. Updated information on vital status (eg, date of death and migration) and cancer incidence by the end of 2012 was obtained. The Cancer Registry comprises information on date of diagnosis, cancer site (ICD-10 code), morphology and stage. The Cancer Registry has stored data on all malignant diseases diagnosed in the Norwegian population since 1953. Mandatory reporting to the Registry from several independent sources ensures completeness and high data quality. ${ }^{16}$ In 2019, the cohort was again linked to the Cancer Registry and the Cause of Death Registry. Updated information on cancer incidence, vital status and cause of death was obtained up to the end of 2017. By the end of follow-up, 1075 (53\%) men 
have been diagnosed with CVD, $838(42 \%)$ with cancer, and $1756(87 \%)$ have died (figure 3$)$.

\section{Patient and public involvement}

There was no patient or public involvement in this study.

\section{FINDINGS TO DATE}

Analyses of the data from the Oslo Ischaemia Study have been presented in about 100 original research articles, and in numerous conference presentations. Results from the Oslo Ischaemia Study have significantly contributed to the understanding of cardiovascular epidemiology. A dozen $\mathrm{ScD}$ or PhD fellows have used data from the Oslo Ischaemia Study in their thesis.

Early study results revealed new and important insights in the field of silent ischaemia. A heavily cited 1976 publication in Circulation showed that one-third of presumably healthy males with a positive exercise ECG (ie, silent ischaemia), in fact, did not have significant stenosis in their coronary arteries. ${ }^{15}$ This was the second publication of its sort globally, but with stronger power than the study by Froelicher et al. ${ }^{17}$ A 7 -year follow-up of these so-called false-positive ECG findings revealed, however, that a large proportion of these men by then had developed heart disease ${ }^{18}$ which prompted an invited review article in Circulation-'False positive exercise ECG: a misnomer'. ${ }^{19}$ Later, results from the Oslo Ischaemia Study showed that a mere $0.5 \mathrm{~mm}$ ST-depression on an exercise ECG was associated with significantly increased incidence of CVD, thereby challenging concurrent guidelines, and the common finding of a rapid upsloping ST-segment was shown to associate with reduced risk of fatal CHD compared with a normal ST-segment. ${ }^{20} 21$

The study has provided substantial results in establishing exercise blood pressure as a predictor for CVD. Erikssen $e t$ al started in 1980 with an attempt to discover normal blood pressure responses to exercise. ${ }^{22}$ With increasing follow-up time, the association grew stronger, and after 21 years of follow-up, moderate workload exercise systolic blood pressure was associated with a 1.4-fold (CI 1.1 to 1.9 ) increased risk of cardiovascular mortality per 2SD increase, which was essentially in the same range as for resting systolic blood pressure. ${ }^{23}$ Evidence emerged supporting the assumption that resting and exercise blood pressure independently predicted CVD and mortality, and it now seems that moderate workload exercise blood pressure is linearly associated with coronary disease, independently from and in a similar manner as resting blood pressure. ${ }^{24}$ In contrast, systolic blood pressure at maximal workload is associated with stroke risk, ${ }^{25}$ and latest research from Oslo Ischaemia Study also shows a J-shaped association between increase in systolic blood pressure at maximal exercise from resting conditions and risk of stroke. ${ }^{26}$ This has led to the hypothesis that elevated blood pressure at moderate stress increases coronary disease, whereas an exaggerated blood pressure response to maximal stress increases risk of cerebral stroke.

Also other parameters derived from the exercise test have provided useful information. Low heart rate at moderate workload, as a marker for increased vagal tone, predicts atrial fibrillation in our cohort. ${ }^{27}$ Two hundred and seventy participants (13\%) developed atrial fibrillation during follow-up, and participants with heart rate less than 100 beats per minute at $100 \mathrm{~W}$ workload, had $60 \%$ increased risk of atrial fibrillation compared with participants with heart rate equal to or above 100 beats per minute at same workload.

Due to extensive data collection and thorough follow-up through many years, the Oslo Ischaemia Study has contributed to several other fields of research beyond silent ischaemia and CHD. Findings in this cohort also challenged the validity of the proposed Stage 0 of the Global Initiative for Chronic Obstructive Lung Disease, which later has been abandoned, ${ }^{28}$ and forced expiratory volume during first second of expiration has proved predictive values beyond pulmonary disease in smokers, as it is associated with all-cause mortality. Results from the Oslo Ischaemia Study shows 8\% increase in all-cause mortality with a $10 \%$ decrease in percentage of predicted forced expiratory volume during first second of expiration $\left(\mathrm{FEV}_{1} \%\right) .^{29}$

Along with a handful other research groups globally, the Oslo Ischaemia Study has been instrumental in defining the implications of objectively measured physical fitness on short-term and long-term cardiovascular health, and specifically, on the ability of physical fitness, as measured by an exercise test, to predict future health in a presumably healthy male population. The definition of physical fitness used in the study is uncommonly used today. However, the method used in Oslo Ischaemia Study has shown a close correlation to maximal oxygen uptake during exercise, the gold standard of physical fitness, and was considered the most feasible method. ${ }^{30}$ In 1982, the study showed an association of low physical fitness and heightened risk of death, ${ }^{31}$ which was followed by a muchcited publication on the association of low fitness and long-term mortality, ${ }^{10}$ and a publication on high fitness and increased longevity. ${ }^{32}$ More recently, with repeated examinations and exercise tests, the study has shown that temporal change in fitness levels, between baseline and the first follow-up visit, was associated with CVD death, ${ }^{33}$ but also that the impact of physical fitness at baseline, declines with time. ${ }^{34}$ Still, improving physical fitness in mid-life halves the risk of stroke compared with those remaining unfit throughout life, and reducing physical fitness in mid-life doubles the risk of stroke compared with those remaining fit throughout their whole life, suggesting that one cannot rest on one's laurels when it comes to fitness. ${ }^{35}$

As more outcome data became available, and linkages to national health registries were performed, the scope of research questions expanded to diseases such as diabetes mellitus ${ }^{36}$ and cancer. ${ }^{3738}$ Also improved physical 
fitness during follow-up was associated with lower cancer incidence and mortality. ${ }^{37}$ The half of the men with the fastest elimination of plasma glucose after an intravenous glucose load had an elevated $60 \%$ risk of cancer compared with the other half. ${ }^{38}$

A brief overview of the publications from the study is given in table 2 , and a comprehensive list of publications is presented in online supplemental table 1.

\section{STRENGTHS AND LIMITATIONS}

The Oslo Ischaemia Study has a prospective study design, strict inclusion criteria of presumably healthy individuals and high response rates. The cohort was comprehensively examined both at baseline and at repeated follow-up examinations that span over decades. The longterm follow-up with complete endpoint registration was enabled through high-quality national registries. The participants were both office and factory workers that were considered representative of the healthy, working male population of Norway. Furthermore, the cohort was representative of the age groups of men within the given time period, with regard to cancer incidence in their counties of residence. ${ }^{39}$ The unique and mandatory personal identification number given at birth enables linkage to several national health registries (eg, the Norwegian Patient Register) which allows us to examine a range of novel research questions. Limitations include the restricted sample size, and that the cohort comprises only presumably healthy Caucasian men in their middle age at inclusion in the early $1970 \mathrm{~s}$, and is not a crosssectional sample. Also a 'healthy worker-effect' may cause some bias in this cohort. Hence, the results cannot be generalised to men of today with a different ethnicity, or be extrapolated to women.

\section{COLLABORATION}

The study has facilitated cooperation between various professionals and fields of medicine, and across national borders. ${ }^{40-42}$ Future collaborations are appreciated. The Oslo Ischaemia Study data is administrated by the Oslo University Hospital. All research projects using data from the Oslo Ischaemia Study need to be approved by the regional committees for medical and health research ethics in Norway. Further information about the Oslo Ischaemia Study is available at wwwosloischemiastudyorg.

\section{Author affiliations}

${ }^{1}$ Oslo Centre for Biostatistics and Epidemiology, Oslo University Hospital, Oslo, Norway

${ }^{2}$ Department of Cardiology, Oslo University Hospital, Oslo, Norway

${ }^{3}$ Vestfold Hospital Trust, Tonsberg, Norway

${ }^{4}$ Institute of Clinical Medicine, University of Oslo, Oslo, Norway

${ }^{5}$ Department of Research, Cancer Registry of Norway, Oslo, Norway

${ }^{6}$ Department of Cardiology, Akershus University Hospital, Lorenskog, Lørenskog,

Norway

${ }^{7}$ Department of Microbiology, Oslo University Hospital, Oslo, Norway

${ }^{8}$ Department of Pulmonary Medicine, Akershus University Hospital, Lørenskog, Norway
${ }^{9}$ Institute of Clinical Medicine, University of Oslo, Lørenskog, Norway

${ }^{10}$ Institute of Informatics, University of Oslo, Oslo, Norway

${ }^{11}$ Department of Paediatric Cardiology, Oslo University Hospital, Oslo, Norway

${ }^{12}$ Department of Nephrology, Oslo University Hospital, Oslo, Norway

Acknowledgements All investigators and authors are in debt to Mrs Ingeborg Erikssen, who for years volunteered to secretarial work.

Contributors JEE was the principal investigator of the study. RSF, EEP and JEM drafted the manuscript. RSF analysed the data. RSF and JB provided the figures. ET, GE, IG, JB, JEE, JVB, KE, KL, KS, LS, PTS, TER, TH provided intellectual inputs to the manuscript. SEK and KG critically revised the manuscript. RSF acted as the guarantor. All authors have read and approved the final version of the manuscript.

Funding The study had initially no funding source, but was made possible through reallocation of internal staff, volunteering and the collaborative agencies. However, in recent years, the Norwegian Council of Cardiovascular Diseases, Stiftelsen Dam, South-East Health Municipality of Norway and Oslo University Hospital, Ullevaal have funded the 0slo Ischaemia Study. Two unrestricted grants have also been received from AstraZeneca (€52 000 in 2010) and Pronova Biopharma Norge AS ( $€ 52000$ in 2011) in connection to scientific collaborations to investigate the risks of cardiovascular mortality and morbidity associated with changes in body mass index, high density cholesterol and triglyceride levels.

Competing interests JB is an epidemiologist employed by AstraZeneca. SEK has within the past 3 years received ad hoc lecture honoraria from Getz, Intas, Merck $\mathrm{KGaA}$ and Sanofi.

Patient consent for publication Not required.

Ethics approval The study was conducted in accordance with the 1964 Helsinki declaration. In 1972, no institutional or regional review board existed in Norway. Hence, no formal institutional approval for the investigation protocol could be obtained. However, the survey protocol was circulated among prominent physicians at two hospitals in 0slo. All participants provided verbal informed consent before inclusion. In the 1990s, after increased awareness of privacy, the Data Protection Authority retrospectively reviewed the inclusion process for the 0slo Ischaemia Study, and judged participation to be in accordance with provisions on written informed consent. Passive informed consent was obtained from all participants alive in 2006. Permission to make a nation-wide search in hospital records was given by the Norwegian Board of Health and the Norwegian Data Inspectorate. Permission to store and analyse unidentifiable person data in the original study was given by the National Data Inspectorate until 2042 (ref.02/00695-7). The Norwegian Board of Health gave their permission to access patients' health files at Norwegian hospitals until 31 December 2008. Permission to link the data to the Cancer Registry of Norway was provided by the Regional Committees for Medical and Health Research Ethics South-East.

Provenance and peer review Not commissioned; externally peer reviewed.

Data availability statement Data are available upon reasonable request. All research using data from the Oslo Ischemia Study has to be approved by the regional committees for medical and health research ethics in Norway. High ethical and legal standard is essential in high-quality research. Data sharing outside Norway requires data transfer agreement governed by the Norwegian law and according to General Data Protection Regulation that applies in EU. Public availability would compromise privacy of the respondents. According to the approval from the Norwegian Regional committees for medical and health research ethics, the data is to be stored properly and in line with the Norwegian Law of privacy protection.

Supplemental material This content has been supplied by the author(s). It has not been vetted by BMJ Publishing Group Limited (BMJ) and may not have been peer-reviewed. Any opinions or recommendations discussed are solely those of the author(s) and are not endorsed by BMJ. BMJ disclaims all liability and responsibility arising from any reliance placed on the content. Where the content includes any translated material, BMJ does not warrant the accuracy and reliability of the translations (including but not limited to local regulations, clinical guidelines, terminology, drug names and drug dosages), and is not responsible for any error and/or omissions arising from translation and adaptation or otherwise.

Open access This is an open access article distributed in accordance with the Creative Commons Attribution Non Commercial (CC BY-NC 4.0) license, which permits others to distribute, remix, adapt, build upon this work non-commercially, and license their derivative works on different terms, provided the original work is properly cited, appropriate credit is given, any changes made indicated, and the use is non-commercial. See: http://creativecommons.org/licenses/by-nc/4.0/. 


\section{ORCID iDs}

Ragnhild Sørum Falk http://orcid.org/0000-0001-8398-3492 Julian Eek Mariampillai http://orcid.org/0000-0002-3857-9797 Erik Edvard Prestgaard http://orcid.org/0000-0003-4051-4148 Trond Heir http://orcid.org/0000-0001-9616-0145 Johan Bodegård http://orcid.org/0000-0001-5423-3967 Trude Eid Robsahm http://orcid.org/0000-0002-1652-7734 Irene Grundvold http://orcid.org/0000-0002-0296-5565 Kristian Engeseth http://orcid.org/0000-0002-0411-6815 Jorgen Vildershoj Bjornholt http://orcid.org/0000-0002-0079-8062

Knut Stavem http://orcid.org/0000-0003-4512-8000

Knut Liestøl http://orcid.org/0000-0002-7929-582X

Gunnar Erikssen http://orcid.org/0000-0002-6400-3097

Sverre E Kjeldsen http://orcid.org/0000-0003-2389-0272

Knut Gjesdal http://orcid.org/0000-0002-3575-0667

\section{REFERENCES}

1 Norwegian Institute of Public Health. Statistics bank. Available: http://www.norgeshelsa.no/norgeshelsa/index.jsp?headers= AAR\&ALDER_DODsubset=0\&stubs=ARSAK\&stubs=KJONN_MK\& measure $=$ common\&virtualslice $=$ RATE $N$ value\&layers $=$ ALDER DOD\&layers=virtual\&study $=\mathrm{http} \% 3 \mathrm{~A} \% 2 \mathrm{~F} \% 2 \mathrm{~F} 10.1 .5 .31 \% 3 \mathrm{~A} 80 \%$ 2Fobj\%2FfStudy\%2F3000eur\&ALDER_DODslice=0\&mode=cube\& $\mathrm{v}=2 \&$ virtualsubset $=$ RATE_N_value\&AARsubset $=1951+-+2006 \&$ measuretype $=4 \&$ cube $=$ http $\% 3 A \% 2 F \% 2 F$ norgeshelsa.no\%3A80\% 2Fobj\%2FfCube\%2F3000eur C1\&KJONN MKsubset=1+-+2\& ARSAKsubset $=0 \% 2 \mathrm{C} 1+-+58 \% 2 \mathrm{C} 2+-+65 \&$ top $=y e s \&$ language $=e n$ [Accessed 06 Jan 2021].

2 Tsao CW, Vasan RS. Cohort profile: the Framingham heart study (FHS): overview of milestones in cardiovascular epidemiology. Int $J$ Epidemiol 2015;44:1800-13.

3 Erikssen J, Enger SC, Smoking ESC. Smoking, lung function, physical performance and latent coronary heart disease in presumably healthy middle-aged men. Acta Med Scand 1978;203:509-16.

4 Bernstein L, D'Silva JL, Mendel D. The effect of the rate of breathing on the maximum breathing capacity determined with a new spirometer. Thorax 1952;7:255-62.

5 Erikssen J, Skrede S. Serum lipids and latent coronary insufficiency. Scand J Clin Lab Invest 1977;37:243-50.

6 Medical Research Council's Committee on the Aetiology of Chronic Bronchitis. Standardized Questionaries on respiratory symptoms. BMJ 1960;2:1665.

7 Rose GA, Blackburn H. Cardiovascular survey methods. Monogr Ser World Health Organ 1968:56:1-188.

8 Frank CW, Weinblatt E, Shapiro S. Angina pectoris in men. prognostic significance of selected medical factors. Circulation 1973:47:509-17.

9 Bodegard J, Erikssen G, Bjørnholt JV, et al. Reasons for terminating an exercise test provide independent prognostic information: 2014 apparently healthy men followed for 26 years. Eur Heart $J$ 2005;26:1394-401.

10 Sandvik L, Erikssen J, Thaulow E, et al. Physical fitness as a predictor of mortality among healthy, middle-aged Norwegian men. $N$ Engl J Med 1993;328:533-7.

11 Thaulow E, Erikssen J, Sandvik L, et al. Blood platelet count and function are related to total and cardiovascular death in apparently healthy men. Circulation 1991;84:613-7.

12 Chr Enger S, Erikssen J. High density lipoproteins, insulin secretion and coronary risk factors in latent coronary insufficiency. Scand $J$ Clin Lab Invest 1979;39:627-34.

13 Stormorken H, Erikssen J. Plasma antithrombin III and factor VIII antigen in relation to angiographic findings, angina and blood groups in middle-aged men. Thromb Haemost 1977;38:0874-80.

14 Erikssen G, Thaulow E, Sandvik L, et al. Haematocrit: a predictor of cardiovascular mortality? J Intern Med 1993;234:493-9.

15 Erikssen J, Enge I, Forfang K, et al. False positive diagnostic tests and coronary angiographic findings in 105 presumably healthy males. Circulation 1976;54:371-6.

16 Larsen IK, Småstuen M, Johannesen TB, et al. Data quality at the cancer registry of Norway: an overview of comparability, completeness, validity and timeliness. Eur $\mathrm{J}$ Cancer 2009;45:1218-31.

17 Froelicher VF, Yanowitz FG, Thompson AJ, et al. The correlation of coronary angiography and the electrocardiographic response to maximal treadmill testing in 76 asymptomatic men. Circulation 1973;48:597-604.

18 Erikssen J, Dale J, Rootwelt K, et al. False suspicion of coronary heart disease: a 7 year follow-up study of 36 apparently healthy middle-aged men. Circulation 1983;68:490-7.

19 Erikssen J, Myhre E. False positive exercise ECG: a misnomer? Int J Cardiol 1984;6:263-8.

20 Bodegard J, Erikssen G, Bjørnholt JV, et al. Symptom-limited exercise testing, St depressions and long-term coronary heart disease mortality in apparently healthy middle-aged men. Eur $J$ Cardiovasc Prev Rehabil 2004;11:320-7.

21 Hodnesdal C, Prestgaard E, Erikssen G, et al. Rapidly upsloping ST-segment on exercise ECG: a marker of reduced coronary heart disease mortality risk. Eur J Prev Cardiol 2013;20:541-8.

22 Erikssen J, Jervell J, Forfang K. Blood pressure responses to bicycle exercise testing in apparently healthy middle-aged men. Cardiology 1980;66:56-63.

23 Kjeldsen SE, Mundal R, Sandvik L, et al. Supine and exercise systolic blood pressure predict cardiovascular death in middle-aged men. $J$ Hypertens 2001;19:1343-8.

24 Mariampillai JE, Liestøl K, Kjeldsen SE, et al. Exercise systolic blood pressure at moderate workload is linearly associated with coronary disease risk in healthy men. Hypertension 2020;75:44-50.

25 Prestgaard E, Hodnesdal C, Engeseth K, et al. Long-term predictors of stroke in healthy middle-aged men. Int J Stroke 2018;13:292-300.

26 Mariampillai JE, Prestgaard EE, Kjeldsen SE, et al. Novel insights into stroke risk beyond resting and maximal bicycle exercise systolic blood pressure. J Hypertens 2021;39:2022-9.

27 Grundvold I, Skretteberg PT, Liestøl K, et al. Low heart rates predict incident atrial fibrillation in healthy middle-aged men. Circ Arrhythm Electrophysiol 2013;6:726-31.

28 Stavem K, Sandvik L, Erikssen J. Can global initiative for chronic obstructive lung disease stage 0 provide prognostic information on long-term mortality in men? Chest 2006;130:318-25.

29 Stavem K, Aaser E, Sandvik L, et al. Lung function, smoking and mortality in a 26 -year follow-up of healthy middle-aged males. Eur Respir J 2005;25:618-25.

30 Bonjer FH. Measurement of working capacity by assessment of the aerobic capacity in a single session. Fed Proc 1966;25:1363-5.

31 Erikssen J, Mundal R. The patient with coronary artery disease without infarction: can a high-risk group be identified? Ann N Y Acad Sci 1982;382:438-49.

32 Heir T, Erikssen J, Sandvik L. Life style and longevity among initially healthy middle-aged men: prospective cohort study. BMC Public Health 2013;13:831.

33 Erikssen G, Liestøl K, Bjørnholt J, et al. Changes in physical fitness and changes in mortality. Lancet 1998;352:759-62.

34 Engeseth K, Prestgaard EE, Mariampillai JE, et al. Physical fitness is a modifiable predictor of early cardiovascular death: a 35-year follow-up study of 2014 healthy middle-aged men. Eur J Prev Cardiol 2018;25:1655-63.

35 Prestgaard E, Mariampillai J, Engeseth $\mathrm{K}$, et al. Change in cardiorespiratory fitness and risk of stroke and death. Stroke 2018:Strokeaha118021798

36 Bjørnholt JV, Erikssen G, Liestøl K, et al. Prediction of type 2 diabetes in healthy middle-aged men with special emphasis on glucose homeostasis. results from 22.5 years' follow-up. Diabet Med 2001;18:261-7.

37 Robsahm TE, Heir T, Sandvik L, et al. Changes in midlife fitness, body mass index, and smoking influence cancer incidence and mortality: a prospective cohort study in men. Cancer Med 2019;8:4875-82

38 Falk RS, Tretli S, Paulsen JE, et al. Response to intravenous glucosetolerance test and risk of cancer: a long-term prospective cohort study. EBioMedicine 2017;21:117-22.

39 Heir T, Falk RS, Robsahm TE, et al. Cholesterol and prostate cancer risk: a long-term prospective cohort study. BMC Cancer 2016;16:643.

40 Farkhooy A, Bodegård J, Erikssen JE, et al. Cross-sectional and longitudinal analyses of the association between lung function and exercise capacity in healthy Norwegian men. BMC Pulm Med 2018;18:118.

41 Skretteberg PT, Grytten AN, Gjertsen K, et al. Triglycerides-diabetes association in healthy middle-aged men: modified by physical fitness? a long term follow-up of 1962 Norwegian men in the Oslo ischemia study. Diabetes Res Clin Pract 2013;101:201-9.

42 Bodegard J, Skretteberg PT, Gjesdal K, et al. Low-grade systolic murmurs in healthy middle-aged individuals: innocent or clinically significant? A 35-year follow-up study of 2014 Norwegian men. $J$ Intern Med 2012;271:581-8. 